\title{
Management and Outcome of Hyperemesis Gravidarum at Tertiary Obstetric Facility, Khartoum-Sudan
}

\author{
Atif B. Fazari1,2,3*, Hasouna Z. S. Ahmed ${ }^{1,4}$, Rasha Eltayeb ${ }^{1,3,5}$, Mohammed H. Ali ${ }^{2,6}$, Khalifa Elmusharaf ${ }^{1,7}$ \\ ${ }^{1}$ Reproductive and Child Health Research Unit, University of Medical Sciences \& Technology, Khartoum, Sudan \\ ${ }^{2}$ Omdurman Maternity Hospital, Ministry of Health, Khartoum, Sudan \\ ${ }^{3}$ Latifa Hospital Dubai Health Authority, Dubai, UAE \\ ${ }^{4}$ Police Hospital Red Sea State, Port Sudan, Sudan \\ ${ }^{5}$ Academy Charity Teaching Hospital, State Ministry of Health, Khartoum, Sudan \\ ${ }^{6}$ Royal Preston Hospital, Lancashire, UK \\ ${ }^{7}$ Graduate Entry Medical School, University of Limerick, Limerick, Ireland \\ Email: *atiffazari@hotmail.co.uk
}

How to cite this paper: Fazari, A.B., Ahmed, H.Z.S., Eltayeb, R., Ali, M.H. and Elmusharaf, K. (2016) Management and Outcome of Hyperemesis Gravidarum at Tertiary Obstetric Facility, Khartoum-Sudan. Open Journal of Obstetrics and Gynecology, 6, 630-636. http://dx.doi.org/10.4236/ojog.2016.611079

Received: July 19, 2016

Accepted: September 19, 2016

Published: September 22, 2016

Copyright $\odot 2016$ by authors and Scientific Research Publishing Inc. This work is licensed under the Creative Commons Attribution International License (CC BY 4.0).

http://creativecommons.org/licenses/by/4.0/

\section{(c) (i) Open Access}

\begin{abstract}
Introduction: Hyperemesis gravidarum ( $\mathrm{HG}$ ) is vomiting and/or nausea in pregnancy causes dehydration, electrolytes imbalance, weight loss and further serious organs dysfunction. Methods: This was a descriptive, prospective, cross-sectional hospital based total coverage analytic study, which was conducted from November 2013 to May 2014 at Omdurman New Hospital (ONH) for Obstetrics \& Gynecology, Khartoum-Sudan. Results: HG prevalence is $13 \%$ of complicated pregnancy of ONH admission. Acetonurea is reported in all cases with significant association between acetonurea and smoking $(P$ value $=0.005)$. A significant association between Hemoglobulin level and the readmission the $(P$ value $=0.01)$ was reported. One maternal death is reported from severe hypoglycemia and liver impairment. Conclusion: Hyperemesis gravidarum has serious maternal morbidity with social negative impacts and significant financial burden on the health services.
\end{abstract}

\section{Keywords}

Hyperemesis Gravidarum, Acetonurea, Maternal Morbidity

\section{Introduction}

Nausea and vomiting of pregnancy affect about $50 \%-90 \%$ of pregnant women in the beginning of the pregnancy and in $20 \%$ of them these symptoms persist through out 
pregnancy [1].

Hyperemesis gravidarum (HG) is defined as vomiting in pregnancy that is sufficiently pernicious to produce weight loss, dehydration, acidosis from starvation, alkalosis from loss of hydrochloric acid in vomitus and hypokalaemia. All these symptoms are not absolutely necessary for the diagnosis [2]. The hypothesis that endocrine factors are the primary cause for HG is often cited. Women with HG often have high human chorionic gonadotrophin (hCG) levels that cause transient hyperthyroidism because hCG can physiologically stimulate the thyroid gland thyroid-stimulating hormone (TSH) receptor as well elevation free T4 levels [3].

The presence of gastrointestinal dysrhythmias is associated with nausea while normal myoelectrical activity of gastrointestinal tract is present in the absence of nausea. Mechanisms that cause gastric dysrhythmias include elevated estrogen or progesterone levels, thyroid disorders, abnormalities in vagal and sympathetic tone and vasopressin secretion in response to intravascular volume perturbation, the gastrointestinal tract more sensitive to these changes in those who develop hyperemesis gravidarum [4].

However, persistent nausea and vomiting beyond the second trimester may be due to an active peptic ulcer caused by $\mathrm{H}$ pylori infection [5].

HG may be a result of an over activated immune system, which could be related to pregnancy hormone synthesis [6]. Immunological factor levels have been studied, and several were found to be higher in HG patients and had positive correlations with the changes in hormone levels [7].

Hyperemesis gravidarum is associated with over activation of sympathetic nerves and enhanced production of tumor necrosis factor (TNF) [8]. Trophoblast-derived cytokines have been reported to induce secretion of hCG causes clear disturbance of immune system results in increased humoral immunity. Thus, Hyperemesis gravidarum may be mediated by immunologic aberrations in pregnancy [9] [10].

Liver function abnormalities have been reported in up to $67 \%$ of cases usually consisting of mild serum transaminase elevation occurs in almost $50 \%$ of patients with Hyperemesis gravidarum. Impairment of mitochondrial fatty acid oxidation (FAO) has been hypothesized to play a role in the pathogenesis of maternal liver disease associated with Hyperemesis gravidarum [11].

Hyperacuity of the olfactory system may be a contributing factor to nausea and vomiting during pregnancy [12] [13].

Considering the psychological causes; HG can be divided into four main categories.

1) HG is an expression of conflicts, such as rejection of the pregnancy, or of an immature personality, strong dependency on the mother, fear of pregnancy.

2) $H G$ is an expression of sexual dysfunction.

3) HG is a conversion symptom, an expression of a hysterical, neurotic, or depressive dysfunction.

4) HG results from psychosocial stress, experienced violence, and/or conflict in the relationship with the partner [14].

The Diagnosis of Hyperemesis gravidarum is a diagnosis of exclusion. Exclusion of 
others differentials is important like Diabetic ketoacidosis (DKA), Malaria, Typhoid fever, Pyelonephritis, viral Hepatitis and Meningitis.

Laboratory Studies are crucial in exclusion of others disorders and confirm HG: Urine analysis for ketones and specific gravity indicate the dehydration and starvation. Renal and liver functions tests are good indicators. Blood glucose level, complete blood count, blood film for Malaria and thyroid functions tests are performed as routine.

Treatment strategies for HG based on the severity of symptoms including hydration, medication, hospitalization and psychosomatic counseling is so necessary. In resisting cases steroids may be one of the options and the termination of pregnancy is the last resort choice in exceptional cases.

Admissions, hydration with fluids and electrolytes correction are important aspects in case management. Fluid replacement should be with either Normal saline $(\mathrm{NaCl}$ $\left.0.9 \% 150 \mathrm{mmol} / \mathrm{L} \mathrm{Na}^{+}\right)$or Hartmann's solutions $\left(\mathrm{NaCl} 0.6 \% 131 \mathrm{mmol} / \mathrm{L} \mathrm{Na}^{+}\right)$are the best for fluid replacement. Intravenous dextrose and carbohydrate rich foods should not be used because they do not contain sufficient sodium to correct hyponatremia and Wernicke's encephalopathy can be precipitated.

Double strength saline should not be used to correct hyponatremia in HG because central pontine myelinolysis can occur if serum sodium level is corrected too rapidly. Relief of symptoms is common within one to two days of rehydration [15].

Diet and nutrition management has role treatment especially with mineral and vitamins supply. Such vitamins have good central nervous system protective action against Wernicke's encephalopathy.

Dietary management generally consists of high carbohydrate, low fat, small meals. Fluids are better tolerated if cold, clear, and carbonated or sour (eg, ginger ale, lemonade), and if taken in small amounts between the meals [16].

Supplements containing iron should be avoided until symptoms resolve, as iron causes gastric irritation \& can provoke nausea and vomiting [17].

Health education for eating habit like pica and others non nutritional habit will help in case treatment.

The cornerstone of non-pharmacologic therapy of Hyperemesis gravidarum is avoidance of environmental triggers, psychological care and nutrition advices.

Throbmoprohylatics measures is considers in all cases.

\section{Methods}

This is a descriptive, prospective, cross-sectional hospital based total coverage analytic study; which was conducted from November-2013 to May 2014 at Omdurman New Hospital (ONH) for Obstetrics \& Gynecology, Khartoum State.

$\mathrm{ONH}$ It is one of the main governmental funded hospitals providing free care in $\mathrm{Ob}$ stetrics and Gynecology. During study period the hospital served 13,721 out of them 6261 were registered deliveries; 142 cases were admitted to the intensive care unit and the reported deaths were 26 cases at the hospital.

Data were collected using specific data collecting sheet designed for this purpose. 
The data was entered, analyzed using Statistical Package for Social Sciences (SPSS) data analysis tool, Version 17 facilities.

Ethical approval was obtained from the Ethical Committee Sudan Medical Specialization Board with signed letter by medical director of the hospital. Inform verbal consent was obtained from cases. The confidentiality was granted through and after the study.

\section{Results}

The total hospital admission during the study period was 1241 for pregnancy complications; out of them 167 were diagnosed as HG that makes prevalence of HG 13\%. 62 cases of the affected women are of age group $15-19$ years $(62 / 167=37.1 \%)$. The majority of studied group are primigravidae $92(92 / 167=55.1 \%)$.

22 patients $(22 / 167=13.2 \%)$ had hospital stay of $1-2$ days, $96(96 / 167=57.5 \%)$ had hospital stay of $3-5$ days, and $43(43 / 167=25.7 \%)$ had hospital stay of 6-8 days and 6 patients $(6 / 167=3.6 \%)$ stayed $9-11$ days (Table 1$)$.

25 cases $(25 / 167=14.9 \%)$ had significant recurrent admission to hospital.

Molar pregnancy is diagnosed in 5 cases $(5 / 167=3 \%)$ and managed according to hospital's protocol for Gestational Trophoblastic Diseases. 6 cases $(6 / 167=3.6 \%)$ have multiple pregnancy and 156 cases (93.4\%) have singleton pregnancy.

The majority of the studied group are low social class; 143 cases $(143 / 167=85.6 \%)$. Significant family history of HG is seen in 122 cases $(122 / 167=73 / 1 \%)$.

Smoking habit is seen in 22 patients $(22 / 167=13.2 \%)$.

Acetonurea is reported in all cases ranged as follow $(++++)$ in 6 cases $(6 / 167=3.6 \%)$, $(+++)$ in 16 cases $(16 / 167=9.6 \%),(++)$ in 51 cases $(51 / 167=30.5 \%)$ and $(+)$ in 94 cases $(94 / 167=56.2 \%)$.

A significant association between acetonuria and smoking is reported ( $P$ value $=$ (0.005)) (Table 2).

Table 1. Distribution of patients according to hospital stay $(\mathrm{N}=167)$.

\begin{tabular}{ccc}
\hline & Frequency & Percent \\
\hline $1-2$ & 22 & $13.2 \%$ \\
$3-5$ & 96 & $57.5 \%$ \\
$6-8$ & 43 & $25.7 \%$ \\
$9-11$ & 6 & $3.6 \%$ \\
Total & 167 & $100 \%$ \\
\hline
\end{tabular}

Table 2. Association of acetonurea and smoking ( $P$ value 0.005$)$.

\begin{tabular}{cccccccc}
\hline & & \multicolumn{5}{c}{ Acetonurea } & Total \\
\cline { 3 - 7 } & & Normal & + & ++ & +++ & ++++ & 22 \\
\hline \multirow{2}{*}{ Smoking } & Yes & 3 & 11 & 1 & 4 & 3 & 145 \\
& No & 13 & 67 & 50 & 12 & 3 & 167 \\
\hline \multirow{2}{*}{ Total } & 16 & 78 & 51 & 16 & 6 & 2 \\
\hline
\end{tabular}


The renal functions test was impaired in 2 cases $(2 / 167=1.2 \%)$, one patient $0.6 \%$ needed dialysis, while 3 cases $(3 / 167=1.8 \%)$ had renal failure that responded to medical treatment.

The liver functions test was abnormal in 6 cases $(6 / 167=3.6 \%)$.

Neurological deficits in the form of inability to walk, obvious abnormal gait and inability to support the neck were observed in 6 patients $(6 / 167=3.6 \%)$.

Hyperthyroidism evidence is seen 17 cases $(17 / 167=10.2 \%)$ however hypothyroidism is reported in 3 cases $(3 / 167=1.8 \%)$ while 147 cases $(147 / 167=88 \%)$ have normal thyroid functions test.

Severe anemia is observed in 2 cases $(2 / 167=1.2 \%)$ of cases and 107 cases $(107 / 167=$ $64.1 \%$ ) had Hemogobulin ( $\mathrm{Hb})$ of $9.5-10.4 \mathrm{gm} / \mathrm{dl}$.

The treatment offered to the patients was according to the hospital's protocol, Hydration with Normal saline and ringer lactate solution, Proton Pump Inhibitors (PPI) and multivitamins injection. Thromboprophylaxis policy was applied. Steroids are needed in four cases and termination of pregnancy is not required. All of patients received psychological evaluation and support.

During the study period there was one maternal death due to severe hypoglycemia with liver impairment.

\section{Discussion}

Hyperemesis gravidarum is a cause for hospital admission in early pregnancy. The prevalence of Hyperemesis gravidarum is $(13 \%)$ this is a high prevalence when compared to the $0.5 \%$ in United States [17], $0.8 \%$ in Canada [18] and in Malaysia 3.9\% [19]. One local published study constituted $10.8 \%$ of the antenatal admission due to Hyperemesis gravidarum [20]. Consisting with others studies most of the affected group is younger age that keeps young maternal age risk factor for HG.

Family history is a risk factor; daughters born from pregnancy affected with hyperemesis gravidarum are more likely to be affected.

There is a significant association between smoking and acetonurea, although some studies showed the incidence of HG decreases with maternal smoking.

Serious organs dysfunctions are confirmed by clinical findings and laboratory tests vary in degree of severity for the liver, kidneys, thyroid central nervous system and hematology.

The hospital stay has great financial burden on the health facility especially that the treatment is offered free of charge to the patient according to the national protocols of Ministry of Health (MOH), it is mentioned in the literature that in American health system spend approximately $130 \$$ million per year while in Germany the cost was 28 million Euro per year. There is no accurate calculation for the cost here in this study but it is clear that a lot of money is spent that makes a financial burden on the health system.

\section{Study Constrains}

Short study period limits subsequent follow of pregnancy outcome. Nausea and vomit- 
ing in early pregnancy are undermined by the family as well most of the health care providers as part of physiology of pregnancy then some cases never reported to the hospital or came late. We note cases came after seeking advice and treatment from traditional healers.

\section{Conclusions}

The prevalence of hyperemesis gravidarum is high. HG is seen in young patients and decreases with advance maternal age and with parity.

HG predisposes serious morbidity different organs and systems and effects quality of life.

Hyperemesis gravidarum has social and family negative impacts with significant financial burden on the health services.

\section{Recommendations}

There is an urgent need to highlight the serious effect of hyperemesis gravidarum. Community awareness with health education helps in attending the health facility for professional care rather to seek it from traditional healers. National guidelines should be formulated for the management of patients with hyperemesis gravidarum.

\section{Acknowledgements}

Special thanks for Dr. Micheal N. Dr. Batera A. and Dr. Mutasim S. for their unlimited generous support and care for Hyperemesis gravidarum patients.

\section{Disclosure}

The authors declare that there is no conflict of interests regarding the publication of this manuscript.

\section{References}

[1] Chan, R.L., Olshan, A.F. and Savitz, D.A. (2010) Nausea and Vomiting and Risk of Spontaneous Abortion. Human Reproduction, 1-6.

[2] Kuscu, N.K. and Koyuncu, F. (2002) Hyperemesis Gravidarum: Current Concepts and Management. Postgraduate Medical Journal, 78, 76-79. http://dx.doi.org/10.1136/pmj.78.916.76

[3] Bottomley, C. and Bourne, T. (2009) Management Strategies for Hyperemesis. Best Practice \& Research Clinical Obstetrics \& Gynaecology, 23, 549-564. http://dx.doi.org/10.1016/j.bpobgyn.2008.12.012

[4] Lee, R.H., Pan, V.L. and Wing, D.A. (2002) The Prevelance of Vomiting of Pregnancy. American Journal of Obstetrics \& Gynecology, 186, S198-S203.

[5] (2005) Helicobacter pylori in the Hispanic Population Affected by Hyperemesis Gravidarum. American Journal of Obstetrics \& Gynecology, 193, 1024-1027.

[6] Minagawa, M., Narita, J., Tada, T., Maruyama, S., Shimizu, T., Bannai, M., Oya, H., Hatakeyama, K. and Abo, T. (1999) Mechanisms Underlying Immunologic States during Pregnancy: Possible Association of the Sympathetic Nervoussystem. Cellular Immunology, 196, 
1-13. http://dx.doi.org/10.1006/cimm.1999.1541

[7] Sekizawa, A., Sugito, Y., Iwasaki, M., Watanabe, A., Jimbo, M., Hoshi, S., Saito, H. and Okai, T. (2001) Cell-Free Fetal DNA Is Increased in Plasma of Women with Hyperemesis Gravidarum. Clinical Chemistry, 47, 2164-2165.

[8] Deruelle, P., Dufour, P., Subtil, D., Houfflin-Debarge, V., Dherbomez, A., Wemeau, J.L. and Puech, F. (2002) Hyperemesis in the First Trimester of Pregnancy: Role of Biological Hyperthyroidism and Fetal Sex. Gynécologie Obstétrique \& Fertilité, 30, 204-209. http://dx.doi.org/10.1016/S1297-9589(02)00296-5

[9] Black, F.O. (2002) Maternal Susceptibility to Nausea and Vomiting of Pregnancy: Is the Vestibular System Involved? American Journal of Obstetrics \& Gynecology, 186, S204S209.

[10] Heinrichs, L. (2002) Linking Olfaction with Nausea and Vomiting of Pregnancy, Recurrent Abortion, Hyperemesis Gravidarum, and Migraine Headache. American Journal of Obstetrics \& Gynecology, 186, S215-S219.

[11] Kaplan, P.B., Gucer, F. and Sayin, N.C. (2003) Maternal Serum Cytokine Levels in Women with Hyperemesis Gravidarum in the First Trimester of Pregnancy. Fertility and Sterility, 79, 498-502. http://dx.doi.org/10.1016/S0015-0282(02)04699-X

[12] Sugito, Y., Sekizawa, A. and Farina, A. (2003) Relationship between Severity of Hyperemesis Gravidarum and Fetal DNA Concentration in Maternal Plasma. Clinical Chemistry, 49, 1667-1669. http://dx.doi.org/10.1373/49.10.1667

[13] Yoneyama, Y., Suzuki, S. and Sawa, R. (2005) Plasma Adenosine Concentrations Increase in Women with Hyperemesis Gravidarum. Clinica Chimica Acta, 352, 75-79. http://dx.doi.org/10.1016/j.cccn.2003.12.026

[14] Verberg, M.F.G., Gillott, D.J., Al-Fardan, N. and Grudzinskas, J.G. (2005) Hyperemesis Gravidarum, a Literature Review. Human Reproduction Update, 11, 527-539. http://dx.doi.org/10.1093/humupd/dmi021

[15] Tan, J.Y., Loh, K.C. and Yeo, G.S. (2002) Transient Hyperthyroidism of Hyperemesis Gravidarum. BJOG, 109, 683-688. http://dx.doi.org/10.1111/j.1471-0528.2002.01223.x

[16] Association of Professors of Gynecology and Obstetrics (2001) Nausea and Vomiting of Pregnancy. Association of Professors of Gynecology and Obstetrics, Washington DC.

[17] Gill, S.K., Maltepe, C. and Koren, G. (2009) The Effectiveness of Discontinuing Iron-Containing Prenatal Multivitamins on Reducing the Severity of Nausea and Vomiting of Pregnancy. Journal of Obstetrics and Gynaecology, 29, 13. http://dx.doi.org/10.1080/01443610802628528

[18] Tan, P.C., Jacob, R., Quek, K.F. and Omar, S.Z. (2006) The Fetal Sex Ratio and Metabolic, Biochemical, Haematological and Clinical Indicators of Severity of Hyperemesis Gravidarum. BJOG, 113, 733-737. http://dx.doi.org/10.1111/j.1471-0528.2006.00947.x

[19] Vikanes, A., Skjaerven, R. and Grjibovski, A.M. (2010) Recurrence of Hyperemesis Gravidarum across Generations: Population Based Cohort Study. BMJ, 340, 2050. http://dx.doi.org/10.1097/ogx.0b013e3182021d24

[20] Elsadig, Y., Lee, A., Mai, M. and Mohamed, A. (2006) The Pattern of Obs\& Gyn Admission in Ribat University Hospital, Khartoum. Sudanese Journal of Public Health, 1. 
Submit or recommend next manuscript to SCIRP and we will provide best service for you:

Accepting pre-submission inquiries through Email, Facebook, LinkedIn, Twitter, etc. A wide selection of journals (inclusive of 9 subjects, more than 200 journals)

Providing 24-hour high-quality service

User-friendly online submission system

Fair and swift peer-review system

Efficient typesetting and proofreading procedure

Display of the result of downloads and visits, as well as the number of cited articles

Maximum dissemination of your research work

Submit your manuscript at: http://papersubmission.scirp.org/

Or contact ojog@scirp.org 